\title{
Boost Chopper Behaviors in Solar Photovoltaic System
}

\author{
Sameer Khader*, Abdel-Karim Daud \\ Palestine Polytechnic University, Department of Electrical Engineering, Hebron, Palestine \\ Email: *sameer@ppu.edu
}

How to cite this paper: Khader, S. and Daud, A.-K. (2021) Boost Chopper Behaviors in Solar Photovoltaic System. Smart Grid and Renewable Energy, 12, 31-52. https://doi.org/10.4236/sgre.2021.123003

Received: March 2, 2021

Accepted: March 28, 2021

Published: March 31, 2021

Copyright (c) 2021 by author(s) and Scientific Research Publishing Inc. This work is licensed under the Creative Commons Attribution International License (CC BY 4.0).

http://creativecommons.org/licenses/by/4.0/ (c) (i) Open Access

\begin{abstract}
This paper investigates the behaviors of Boost DC Chopper used in Photovoltaic energy systems where the solar irradiation changes during the day time causing current and voltage changes. Varying the solar irradiation causes output chopper voltage changes in order to keep working at maximum extracted solar power. The chopper voltage changes leading to variable duty cycle operation of chopper switch and causes a significant change in switch losses in terms of the dissipated power. In addition to that the chopper behaviors are studied when the chopper voltage is boosting up to a predetermined reference value leading to a significant change in chopper current, voltage, duty cycle and occurred losses. A mathematical model for chopper performances and switch losses is derived, and a simulation model using Matlab/ Simulink platforms is conducted to follow the chopper behaviors. Simulation results for concreteSUNPOWER panel type SPR-315E-WHT-D with 315 Watts peak indicates that during the daylight time transistors are exposed to complicated changes in their current, voltage and dissipated power. Furthermore changing the output voltage according to load requirements causes heavy stress on the transistor in terms of current, oscillations and losses as well. Simulation results show that there are optimized values of irradiation, chopper voltage and duty cycle where the transistor losses are minimized. In addition to that, projecting the transistor losses over the daylight time at a given irradiation rate shows how these losses vary among the year, and the amount of energy dissipated across the main chopper switch which is around $2970 \mathrm{Whr} / \mathrm{yr}$ for the present case. Furthermore, the conducted simulation also shows the occurred in the transistor behaviors when solar irradiation changes, and can be serving for further studies.
\end{abstract}

\section{Keywords}

DC-DC Converters, Photovoltaic Source, PWM, Buck-Boost, Boost Converters 


\section{Introduction}

Photovoltaic power is considered as a promised source for present and future generations aiming at reducing the gas emissions causes by conventional energy sources such as fossil and cool sources [1]. Therefore, it is worth mentioning to investigate alternative clean energy sources and related conversion modules [2] [3]. AS well know photovoltaic systems consist of photovoltaic source (PV), dc to dc converter that can be boost or buck boost chopper, dc link and filter, dc to ac converter (inverter) that can be single or multiphase voltage source or current source inverter, and output AC filter that can be C, LC, CL, and CLC filter [4] [5]. In the photovoltaic solar system the most used choppers are either boost or buck-boost in order to vary the voltage to be at the maximum power point by varying the operation time of the chopper switch throughout varying the duty cycle [5].

Various research articles describing the behaviors of chopper elements mainly transistor switch (MOSFET) with respect to current, dissipated power, and switch current distortion [6] [7]. The occurred losses vary significantly as the irradiation level changes during the day time, and that varies seasonally, therefore optimized chopper's configuration could be a subject for further investigations.

With respect to the signal quality a pulse width modulation converters (PWM) is used in combination with a maximum power tracker module using perturb and observation approach $(\mathrm{P} \& \mathrm{O})$. The produced unwanted voltage and current harmonics that are limited by increasing the rate of the modulation frequency of both chopper frequency and inverter frequency [8] [9] reduces the size of the used filter but causes a significant change in chopper losses. Decreasing the chopper losses and size of chopper elements can be achieved by proposing modified chopper configurations as illustrated in [10] [11].

The importance of this work:

The described mathematical models for determining the occurred in the chopper losses are concentrated over the non-linearity change of these losses for a given instant of time, while the present work gives an integrity approach for these losses for a wide interval of time and can give an estimated amount of dissipated energy among the year for the most important chopper's element which is the power transistor.

The main aims of this paper are:

- Deriving mathematical expressions that presenting the chopper duty cycle, current and losses with respect to the local irradiation, and projecting the proposed model for certain chopper and panel data.

- Determining the irradiation rate at which chopper switches dissipate minimum heat in terms of drawn power.

- Determining the duty cycle operation ranges at which the losses are maintained at minimized level.

- Presenting these behaviors in terms of integral annual energy value. 


\section{Mathematical Modeling and Simulation}

Refer to the proposed on Figure 1 principle PV-Boost system, where the generated from the PV source power is maintained at maximum value $P_{m p p}$ according to the solar irradiation level. After that this voltage is regulated throughout boost chopper with modified control to maintain the chopper voltage $V_{c h}$ at that value corresponding to the maximum power extracted and corresponding reference voltage $V_{\text {ref }}$

\subsection{The Concept of Boost Chopper}

As previously mentioned, Boost converters are used to raise up the output voltage to a large values by transferring the accumulated in the inductor energy which is converted into a voltage to the output. Figure 2 illustrates conventional boos converter having main inductor element $L_{1}$, chopper switch $Q_{1}$, bypass diode $D_{1}$ to prevent back capacitor discharge and capacitance $C_{1}$.

The function of $L_{1}$ is transferring energy to the load during off-state of the chopper switch and to maintain continuous current mode, while the function of $C_{1}$ is to energize the load during on-state of the chopper switch, and to reduce the output voltage ripples.

\subsection{Mathematical Model of Boost Chopper}

Taking into account the principle chopper's time-diagram shown on Figure 3, where the inductance voltage and current waveforms are displayed during two transistor operation modes. The inductance voltage during on-state interval with $0 \leq t \leq D T$ by assuming linear current change due to large value of the inductance is given by (1), [2].

$$
V_{L 1}(\text { on })=V_{P V}=L_{1} \frac{\mathrm{d} i_{L}(\text { on })}{\mathrm{d} t(\text { on })} \cong L_{1} \frac{\Delta i_{L_{\text {on }}}}{\Delta T_{\text {on }}}=L_{1} \frac{\Delta i_{L_{\text {on }}}}{D T} .
$$

where $T$ is the chopper switching period, $D$ is the duty cycle, $i_{L}$ is the inductor current, and $i_{P V}$ is the solar panel current. For this circuit $i_{L}=i_{P V}$.

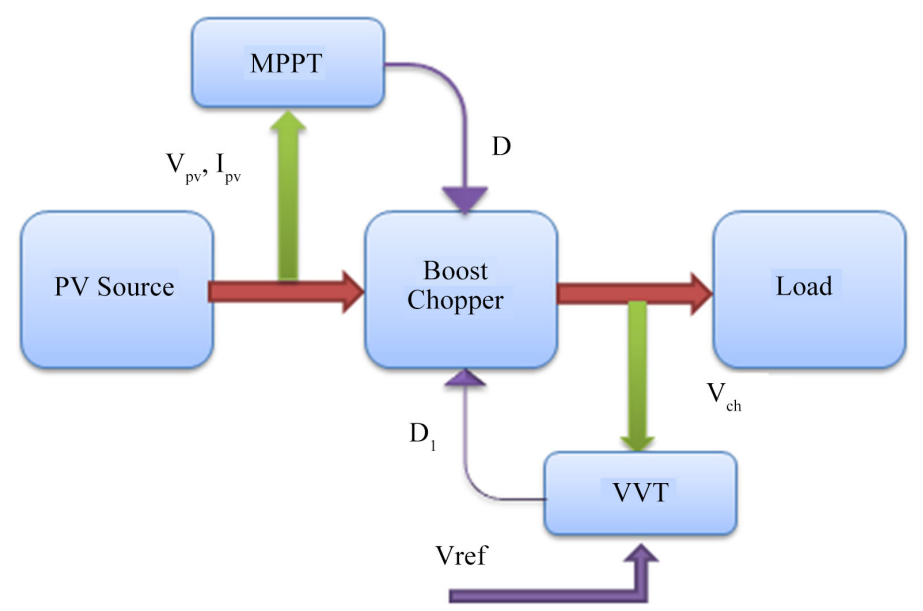

Figure 1. Principle of solar-PV system. 


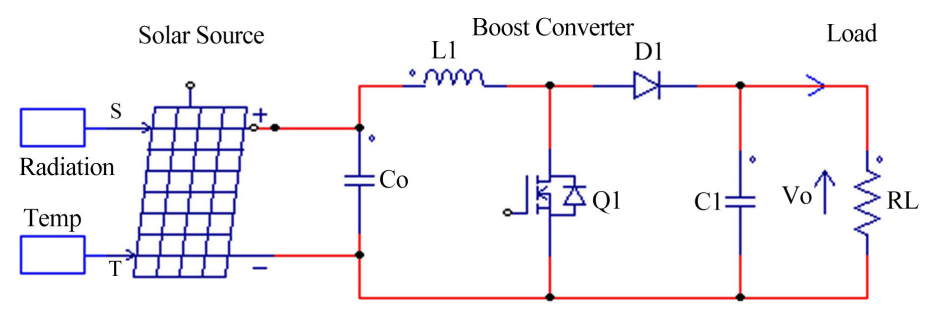

(a)

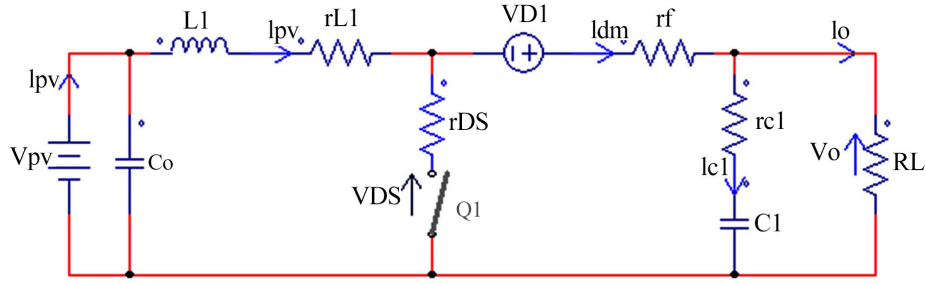

(b)

Figure 2. PV-boost chopper circuit. (a) Conventional configuration; (b) Equivalent circuit.

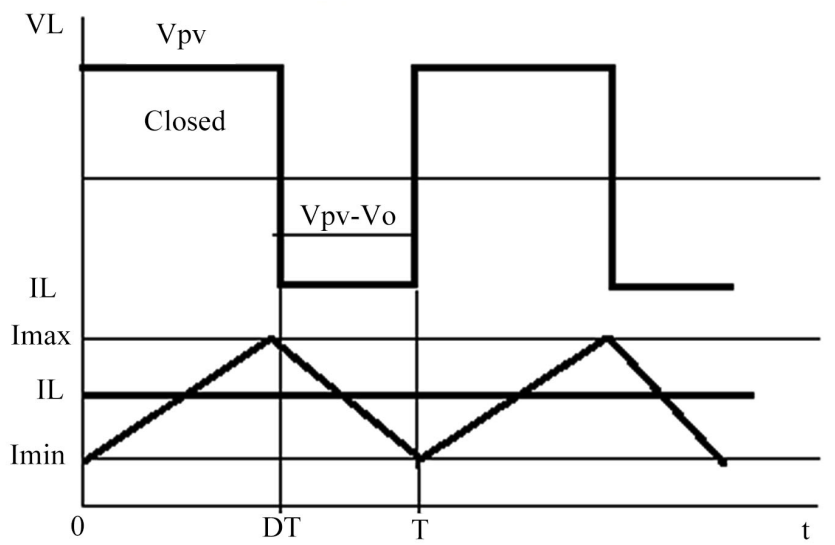

(a)

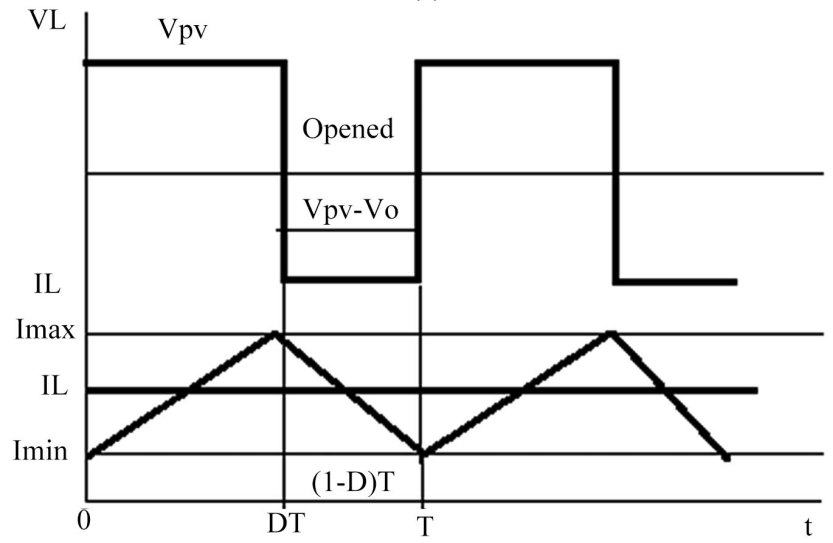

(b)

Figure 3. Chopper waveforms. (a) During on-state; (b) During off-state.

The inductance voltage during the off-state interval with $D T \leq t \leq(1-D) T$ is given by (2). 


$$
V_{L 1}(\text { off })=V_{P V}-V_{o}=L_{1} \frac{\mathrm{d} i_{L}(\text { off })}{\mathrm{d} t}(\text { off }) \cong L_{1} \frac{\Delta i_{L_{\text {off }}}}{\Delta T_{\text {onoff }}}=L_{1} \frac{\Delta i_{L_{\text {off }}}}{(1-D) T}
$$

Taking into account that at steady state the net change in the inductor currents among one period equals zero, and these currents have linear change due to high inductive character of the complete circuit, therefore combining (1) and (2) yields:

$$
\begin{aligned}
& \Delta i_{L_{\text {on }}}+\Delta i_{L_{\text {off }}}=\frac{V_{P V}}{L_{1}} D T+\frac{V_{P V}-V_{o}}{L_{1}}(1-D) T=0 . \\
& \therefore \rightarrow V_{o}=\frac{V_{P V}}{1-D} \text {; and } I_{O}=\frac{V_{o}}{R_{L}} .
\end{aligned}
$$

where $V_{O}, I_{O}$ are the load voltage and current respectively, and $R_{L}$ is the load resistance.

The critical inductance $L_{c r}$ needed to realize continuous current mode is given by (4).

$$
L_{c r}=\frac{(1-D)}{2 f} R_{L}
$$

where $f$ is the chopping frequency.

The required capacitance needed to realize minimum voltage ripples is given by the (5).

$$
C_{1}=\frac{D}{\left(\frac{\Delta V_{o}}{V_{o}}\right) f \cdot R_{L}} .
$$

where $\left(\frac{\Delta V_{o}}{V_{o}}\right)$ is the output voltage ripples.

\section{The dissipated power of the circuit can be divided into:}

1) Inductor conduction losses due to internal inductor resistance $r_{L 1}$ can be expressed as in (6).

$$
P r_{L 1}=r_{L 1} \cdot I_{L r m s}^{2}=r_{L 1} \cdot\left(I_{L 1}^{2}+\left(\frac{\Delta I_{L 1}^{2}}{2 \sqrt{3}}\right)\right) .
$$

where, $\Delta I_{L 1}=\frac{V_{P V} \cdot D}{L_{c r} \cdot f}$ presents the current change at the end of the on-state mode.

$$
I_{L 1}=\frac{V_{P V}}{R_{L}(1-D)^{2}} \text {-the average inductor current over complete switching pe- }
$$
riod.

2) The switch (Transistor) conduction loss due to internal bulk resistance $r_{D S}$ during on-state mode is stated in (7).

$$
P r_{D S}=r_{D S} \cdot I_{D S}^{2}=r_{D S} \frac{D}{3}\left(4 I_{\min }^{2}+I_{\max }^{2}-2 I_{\min } \cdot I_{\max }\right) .
$$


where the minimum and maximum current can be stated as follow:

$$
I_{\min }=\frac{V_{P V}}{R_{L}(1-D)^{2}}-\frac{V_{P V} \cdot D}{2 L_{c r} \cdot f} ; I_{\max }=\frac{V_{P V}}{R_{L}(1-D)^{2}}-\frac{V_{P V} \cdot D}{2 L_{c r} \cdot f} .
$$

3) The diode conduction loss due to internal bulk resistance $r_{f}$ during on-stateinterval is stated as in (9).

$$
P r_{f}=r_{f} \cdot I_{D M}^{2}=r_{f} \cdot \frac{(1-D)}{3}\left(4 I_{\min }^{2}+I_{\max }^{2}-2 I_{\min } \cdot I_{\max }\right) .
$$

4) The capacitance conduction loss due to internal resistance $r_{C}$ among the operation period can be expressed as in (10):

$$
\operatorname{Pr}_{C 1}=r_{C 1} \cdot I_{C 1}^{2}=r_{C 1}\left[D\left(I_{O}^{2}-I_{\max }^{2}\right)+I_{\max }^{2}\right] .
$$

Combining (6) to (10), the total chopper loss during one operation period is stated in (11).

$$
P_{\text {Loss }}=P r_{L 1}+P r_{D S}+P r_{f}+P r_{C 1} \text {. }
$$

Because of this paper is concentration on the boost chopper behaviors, and the transistor switch presents the power driver of the circuit, therefore the following description should only be focused on transistor losses $P r_{D S}$.

\subsection{The Effect of Solar Irradiation Variation}

When solar irradiation intensity varies during the day time causes significant change in the extracted power in terms of voltage and current at given temperature. The significant variation occurs in the generated current, while light change in the voltage. In order to estimate the effect of these parameters on the circuit performances there is a need to derive system parameters in terms of solar irradiation $G$ as follows:

\subsubsection{Photovoltaic Parameters}

According to the equivalent circuit of solar cell displayed on Figure 4 where the solar irradiation is converted into photo current $I_{p h}$ [12] [13]. Based on this circuit, the cell voltage at standard test conditions can be stated according to (12), [14].

$$
V_{p v}=\frac{A \cdot K \cdot T_{c}}{q} \ln \left(\frac{I_{p h}+I_{d}-I_{p v}}{I_{p v}}\right)-R_{s} \cdot I_{p v} .
$$

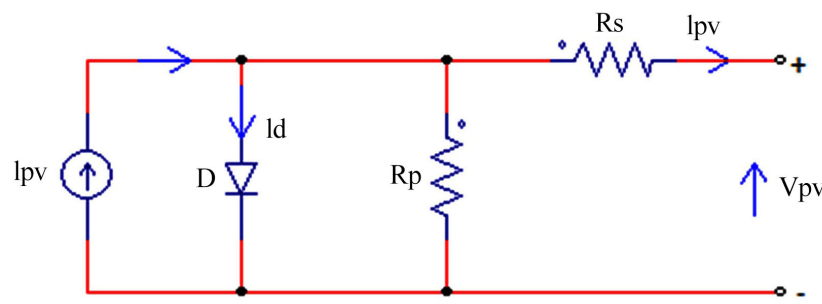

Figure 4. Equivalent circuit for PV cell, [14]. 
where, $A$ is diode idealistic factor, $G_{r}$ is the reference solar irradiation; $I_{d}$ is the diode saturation current; $I_{p h}$ is the cell photo current, $I_{P V}$ is the Photovoltaic current, $I_{S C}$ is the shortcircuit current, $K$ is Boltzmann constant, $q$ is the electric charge, and $R_{s}$ is the $\mathrm{PV}$ intersinc series resistance. The photo current in terms of irradiation and temperature is stated in (13).

$$
I_{p h}=N_{p} \cdot\left[I_{s c} \cdot \frac{G}{G_{r}}+I_{t}\left(T_{c}-T_{r}\right)\right] .
$$

The output cell current is

$$
I_{p v}=N_{p}\left(I_{p h}-I_{d}\left(\mathrm{e}^{\frac{q \cdot V_{o} / N_{s}}{A \cdot K \cdot T_{c}}}-1\right)\right) .
$$

The diode current can be stated as

$$
I_{d}=I_{o r}\left(\frac{T_{c}}{T_{r}}\right)^{3} \cdot \mathrm{e}^{\frac{q \cdot E_{g}}{B \cdot K}\left(\frac{1}{T_{r}}-\frac{1}{T_{c}}\right)}
$$

where, $B$ is diode idealistic factor, $E_{g}$ is the band gap energy of the semiconductor, $T_{C}, T_{r}$ are the cell and reference temperature respectively; $I_{o r} I_{t}$ are constants given at standard conditions. The idealistic diode factors $A \& B$ are with values vary between 1 and 2 depending on I-V performance shaping and approximations.

\subsubsection{Photovoltaic Performance}

Taking into account the stated data in Table 1 for SUNPOWER photovoltaic panel type SPR-315E-WHT-D with 315 Watts peak [15] with conversion efficiency of $19.3 \%$, where the panel I-V performances are shown on Figure 5 for various irradiation rates.

Figure 6 illustrates the Simulink model [16] of PV panel and the obtained current and power performances as function of the photovoltaic voltage. As well shown from Figure 5 and Figure 6 there is a fully coincidence between the catalogue and simulated performances at full sun.

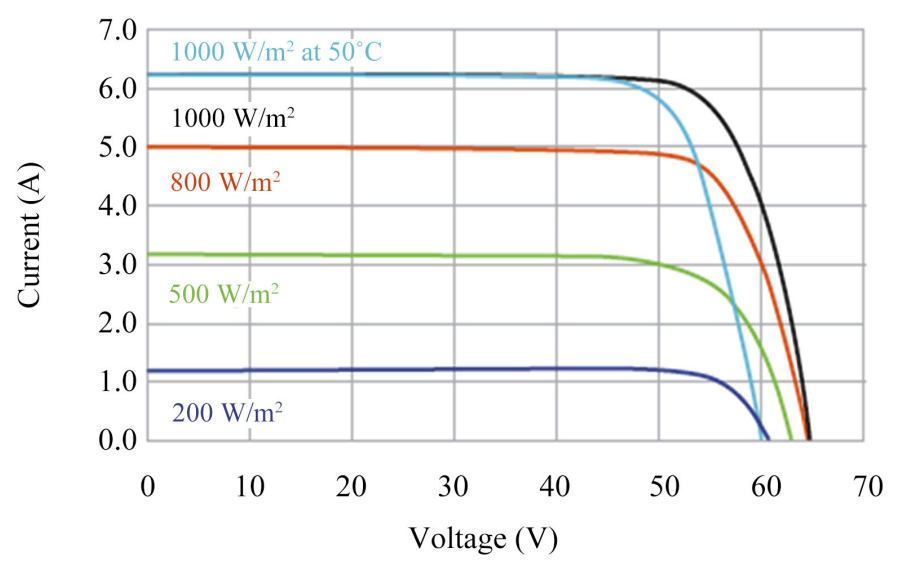

Figure 5. Panel I-V characteristics [15]. 


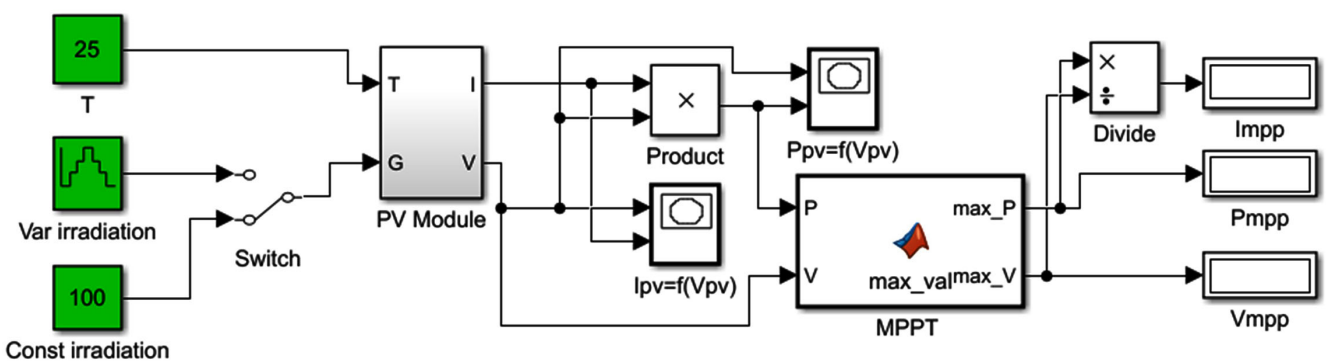

(a)

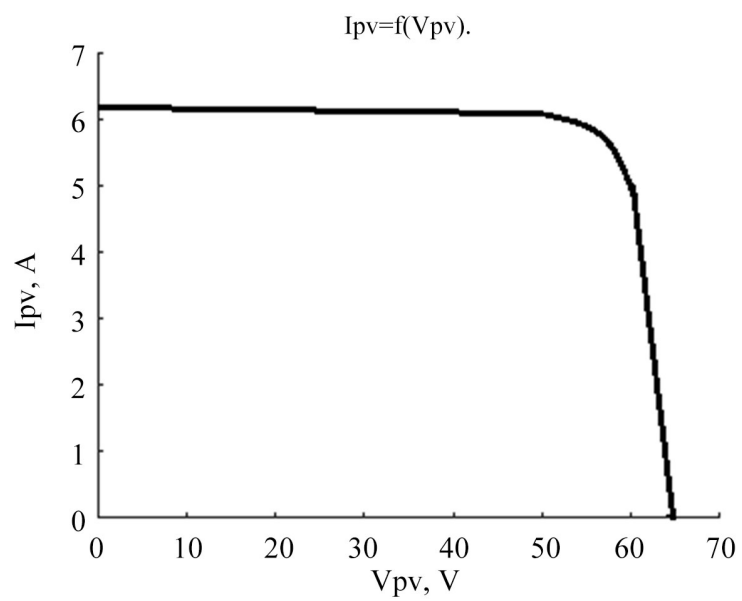

(b)

Figure 6. Simulink model \& panel current at $1000 \mathrm{~W} / \mathrm{m}^{2}$ at standard test conditions. (a) Simulation program; (b) Panel current.

Table 1. Data specification for SPR-315E-WHT-D.

\begin{tabular}{cccccc}
\hline$q$ & $K$ & $I_{p h}$ & $I_{d}$ & $R_{S}$ & $R_{P}$ \\
\hline $1.602 \mathrm{e}-19 \mathrm{C}$ & $1.38 \mathrm{e}-23 \mathrm{~J} /{ }^{\circ} \mathrm{K}$ & $6.14 \mathrm{~A}$ & $0.059 \mathrm{~A}$ & $0.15 \Omega$ & $1090 \Omega$ \\
$N_{S}$ & $N_{P}$ & $V_{\text {cell }}$ & $V_{O C}$ & $I_{S C}$ & $V_{M P P}$ \\
32 & 3 & $0.6 \mathrm{~V}$ & $64.6 \mathrm{~V}$ & $6.14 \mathrm{~A}$ & $54.7 \mathrm{~V}$ \\
$I_{M P P}$ & $E_{g}$ & $N_{P m}$ & $V_{P V}$ & $R_{\text {load }}$ & $T_{C}$ \\
$5.76 \mathrm{~A}$ & 1.1 & 1 & $54.7 \mathrm{~V}$ & $9.6 \Omega$ & $25^{\circ} \mathrm{C}$ \\
\hline
\end{tabular}

\section{Simulation Results and Analysis}

\subsection{Matching between the Chopper Parameters \& Irradiations}

There are several chopper parameters that varies proportionally or inversely as the solar irradiation changes. The most important parameters are maximum power point parameters $V_{M P P}, I_{M P P}$, duty cycle $D$, transistor current, transistor current ratio CRI, transistor losses $P_{\text {LOSS, }}$ dissipated daily and annual energy.

The simulation program is built in Matlab/Simulink environment as shown on Figure 7(a), while Figure 7(b) shows the solar irradiation change $G$, the chopper and reference voltages, the PVand chopper power as the irradiation varies during the day time. 


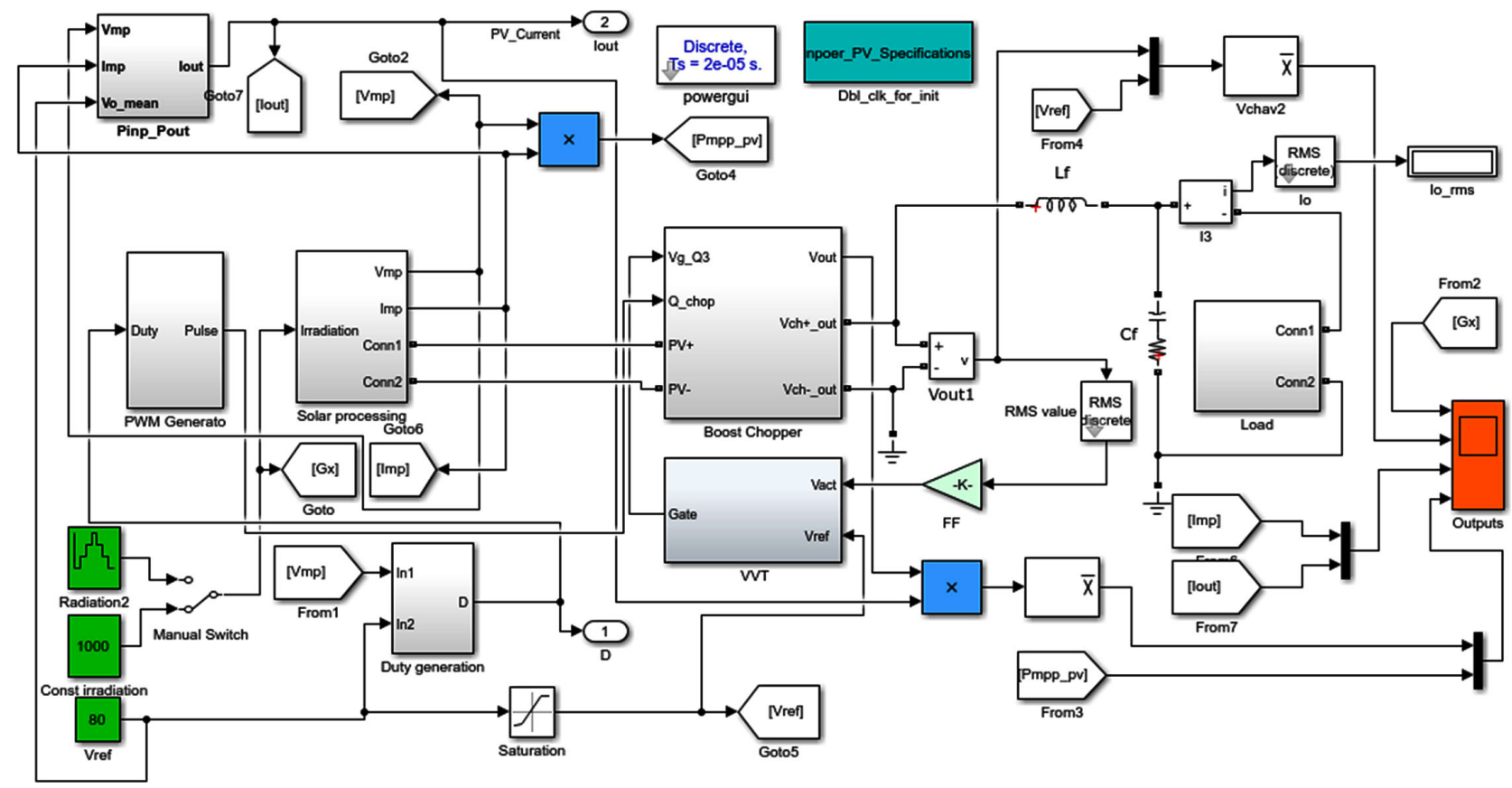

(a)
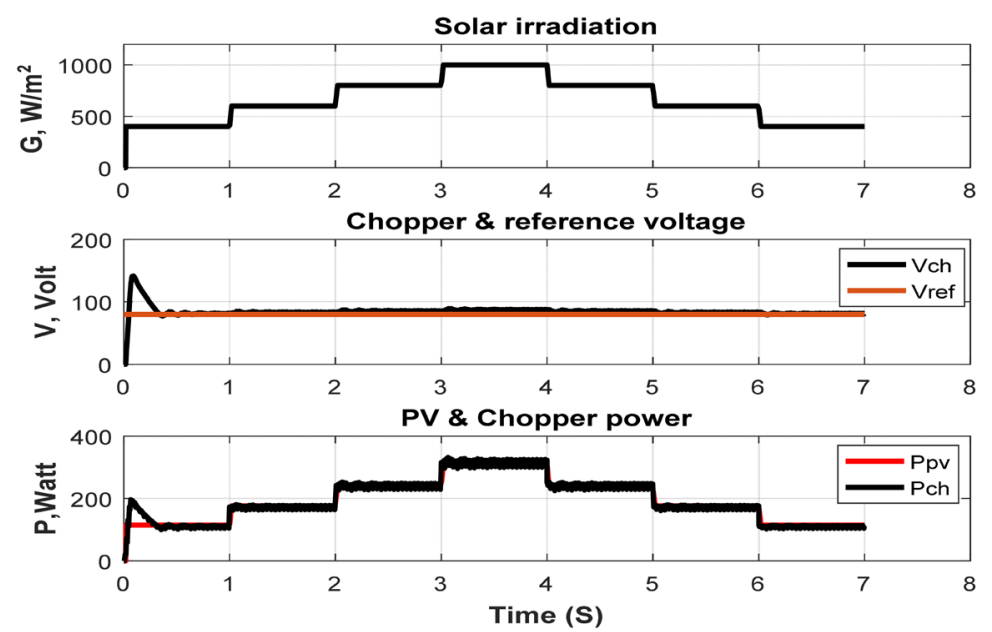

(b)

Figure 7. PV-Chopper simulation \& results. (a) Matlab/SIMULINK program; (b) Irradiation levels, voltages and powers.

\subsubsection{The Effect of Solar Irradiation Change}

Varying the solar irradiation has direct effect on chopper parameters as follow:

\section{1) The voltage change}

The relationship between the voltage at maximum power point $V_{M P P}$ and the solar irradiation is displayed on Figure 8 where the discrete values of $V_{M P P}=f(G)$ are interpolated and converted into continuous performance using spline interpolation in Matlab environment with mathematical expression stated in (16).

$$
V_{M P P}=a_{3} G^{3}+a_{2} G^{2}+a_{1} G+a_{0} .
$$

where $a_{0}, a_{1}, a_{2}$ and $a_{3}$ are irradiation coefficients with approximated values for the described PV panel data. 


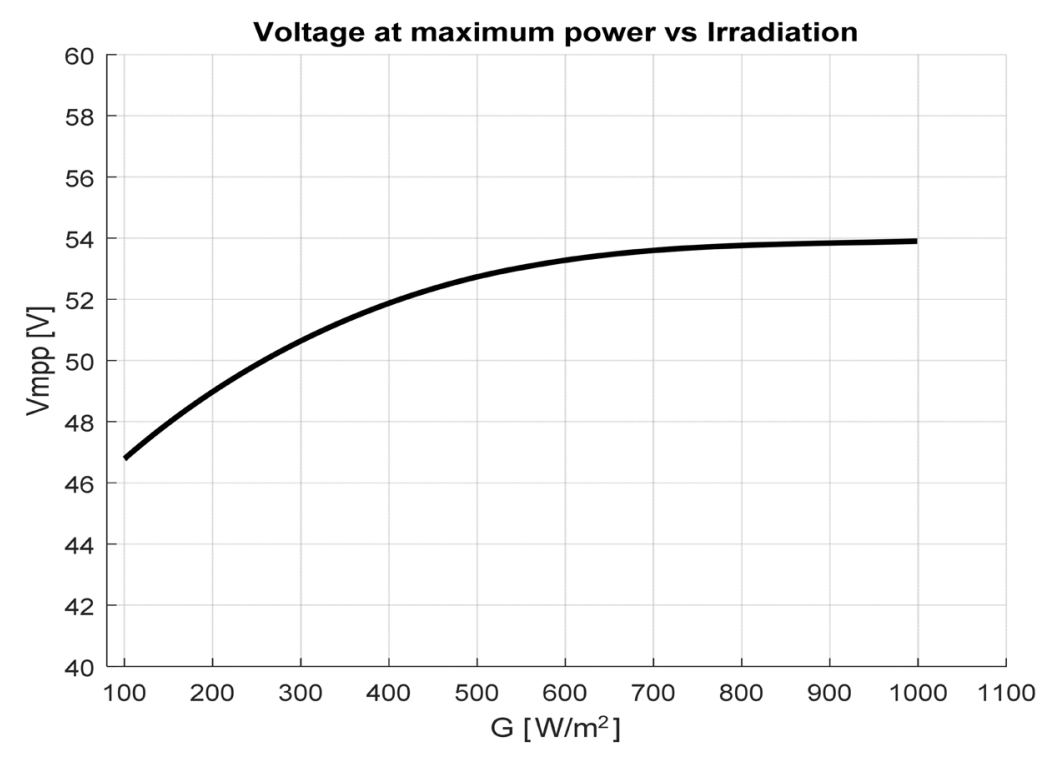

Figure 8. PV voltage at MPP.

$$
a_{3}=1.2 \times 10^{-8}, a_{2}=-3.31 \times 10^{-5}, a_{1}=0.031, a_{0}=44 .
$$

\section{2) Duty cycle change}

The duty cycle change as the solar irradiation varies at constant reference voltage form $55 \mathrm{~V}$ to $120 \mathrm{~V}$ is illustrated on Figure 9 and according to (3), where it can be noticed that at $V_{\text {ref }}=55 \mathrm{~V}$ which is closed to rated value of $V_{M P P}$ at full sun the duty cycle becomes $D \cong 0$, while at $V_{\text {ref }}=120 \mathrm{~V}$ the duty cycle becomes $D \cong 55 \%$.

\section{3) Transistor current at variousirradiation}

Transistor current $I_{Q}=f(G)$ at reference voltage of $V_{\text {ref }}=120 \mathrm{~V}$ is illustrated on Figure 10(a) where this current has complicated character with maximum value at certain irradiation, where this current can be presented with approximated expression stated in (17).

$$
I_{Q}=b_{4} G^{4}+b_{3} G^{3}+b_{2} G^{2}+b_{1} G+b_{0}
$$

where the irradiation coefficients are:

$$
b_{4}=6.2 \times 10^{-12}, b_{3}=-1.7 \times 10^{-8}, b_{2}=1.5 \times 10^{-5}, b_{1}=-0.0049, b_{0}=2.5 \text {. }
$$

It can be noticed that at certain irradiation $G=600-800 \mathrm{~W} / \mathrm{m}^{2}$ the transistor passes large current comparing with other irradiation levels which means the transistor dissipated excess heat before and after noon time as shown on Figure 10(b).

\subsubsection{The Effect of Reference Voltage Change}

Varying the reference voltage forces the chopper to work at different values of duty cycle, which in turn causes transistor conduction time variation; therefore further investigations are required to study chopper parameters' behaviors as follow:

\section{1) Average transistor current}




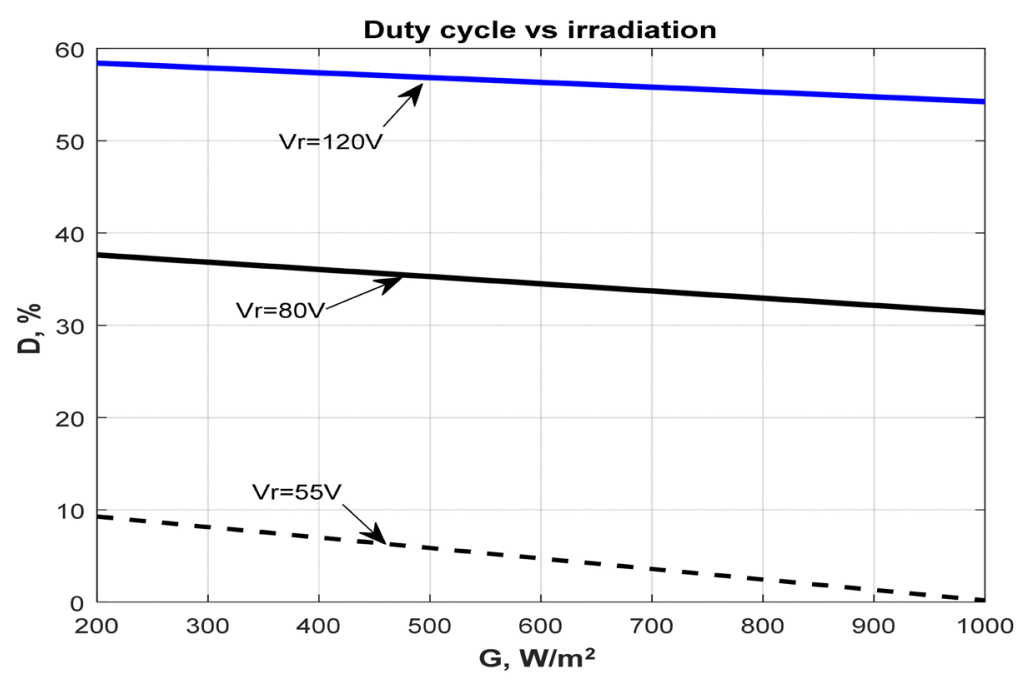

Figure 9. PV voltage at MPP.

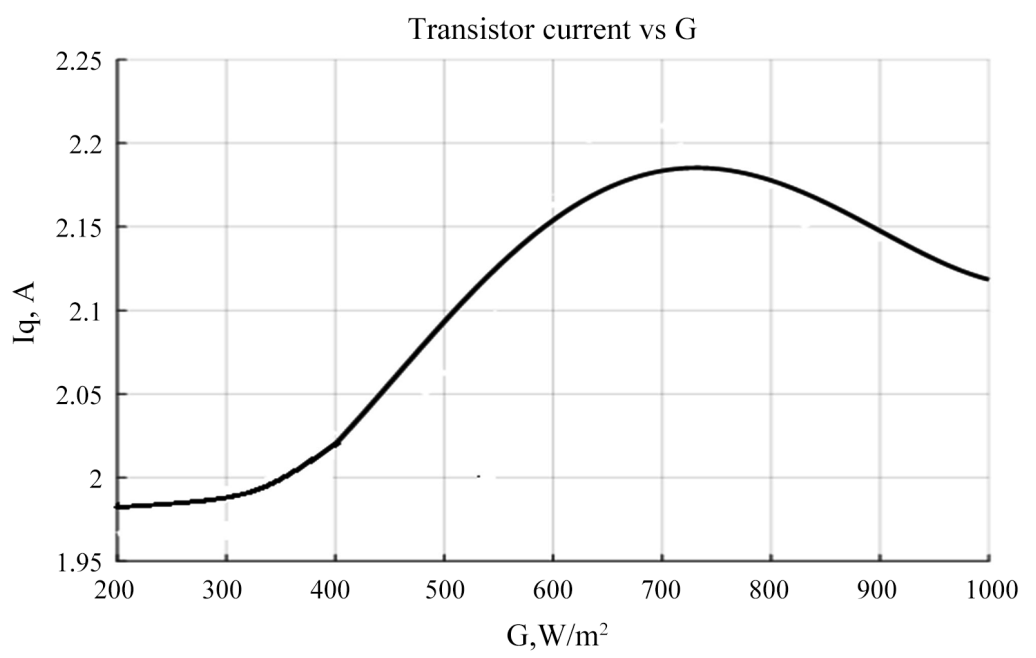

(a)

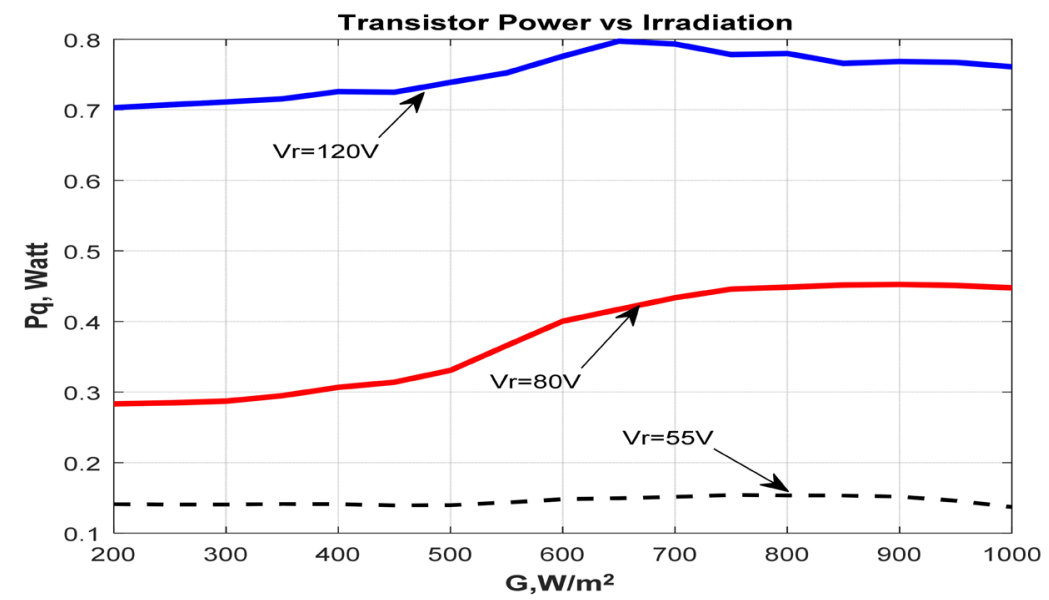

(b)

Figure 10. Transistor current and losses vs. irradiations. (a) Transistor current at Vref $=120 \mathrm{~V}$; (b) Transistor losses. 
Figure 11 illustrates the average transistor current at full sun and variable reference voltage, where the current has mathematical expression stated in (18) which indicates that at low reference voltage the transistor passes low current, while at high voltage the current becomes large and causes huge losses.

$$
I_{Q A V g}=a_{v 4} Z^{4}+a_{v 3} Z^{3}+a_{v 2} Z^{2}+a_{v 1} Z+a_{v 0} .
$$

where $Z=\frac{V_{\text {ref }}-85}{21}$;

$$
a_{v 4}=-0.016, a_{v 3}=-0.097, a_{v 2}=0.056, a_{v 1}=0.73, a_{v 0}=0.83 \text {. }
$$

\section{2) Transistor dissipated losses}

Changing the values of reference voltage leads to significant change in the occurred losses as well shown on Figure 12 for different values of this voltage. The obtained spline function for these losses is stated in (19).

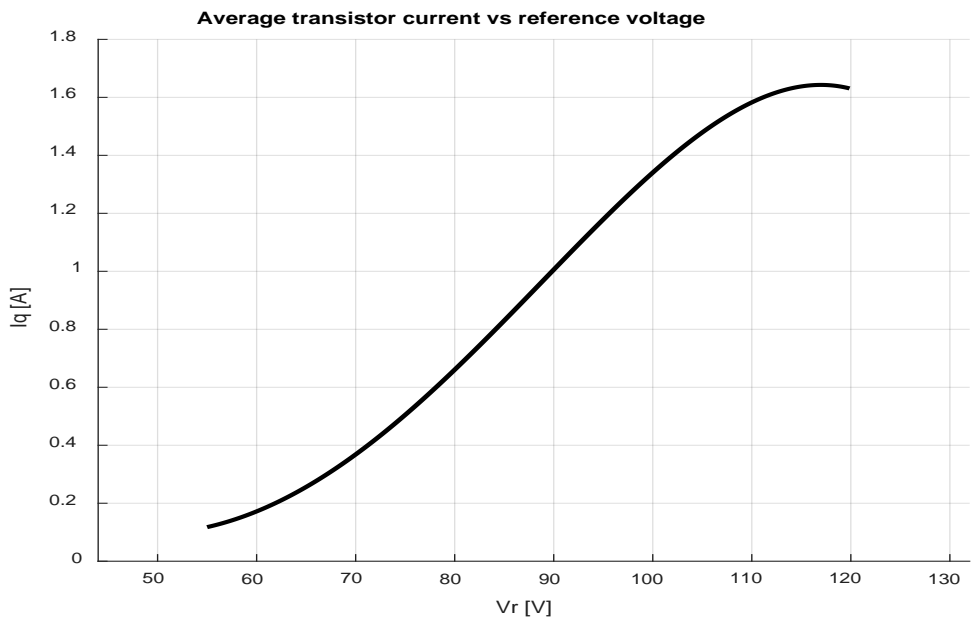

Figure 11. Transistor current.

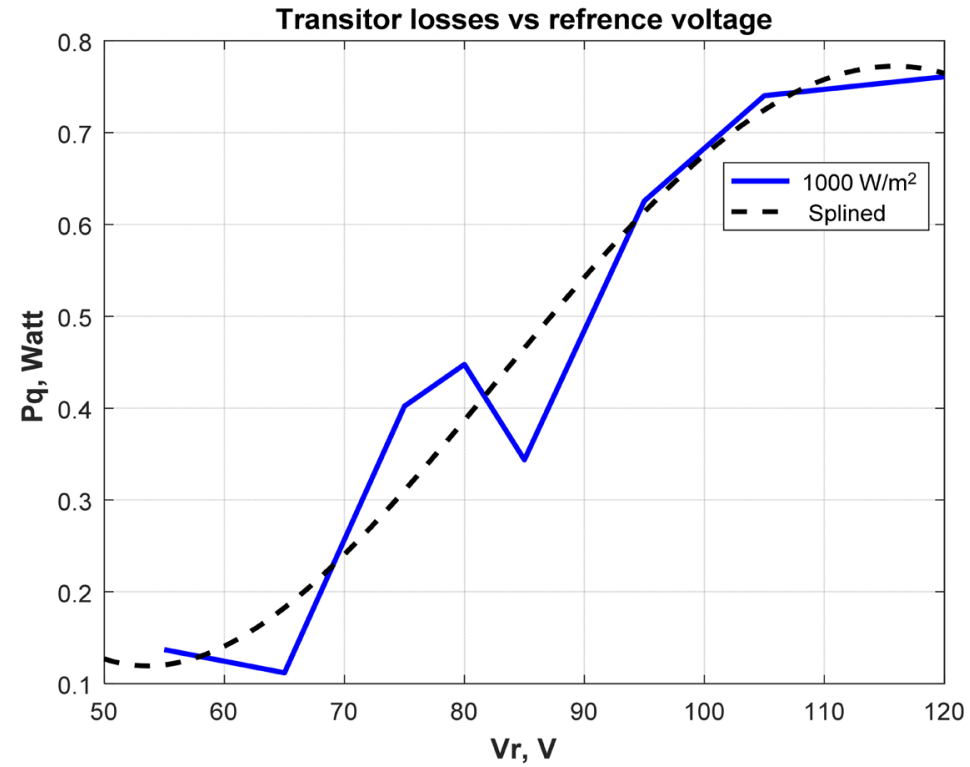

Figure 12. Transistor losses before and after interpolation. 


$$
P_{Q A V g}=a_{q 4} Z^{4}+a_{q 3} Z^{3}+a_{q 2} Z^{2}+a_{q 1} Z+a_{q 0} .
$$

where $a_{q 4}=-0.081, a_{q 3}=0.074, a_{q 2}=0.056, a_{q 1}=0.062, a_{q 0}=0.32$.

\section{3) Average transistorcurrent's ratio}

In order to study the effect of generated current harmonics and oscillations an average current ration indicator CRI is introduced presenting the ratio between transistor RMS current and average current for $G_{i}=200 \ldots 1000 \mathrm{~W} / \mathrm{m}^{2}$.

Figure13(a) illustrates the instantaneous current ration as function of the irradiation, and average ration as function of the reference voltage Figure 13(b), where it's shown that there are concrete reference voltage values where $C_{R I}$ has minimum values.

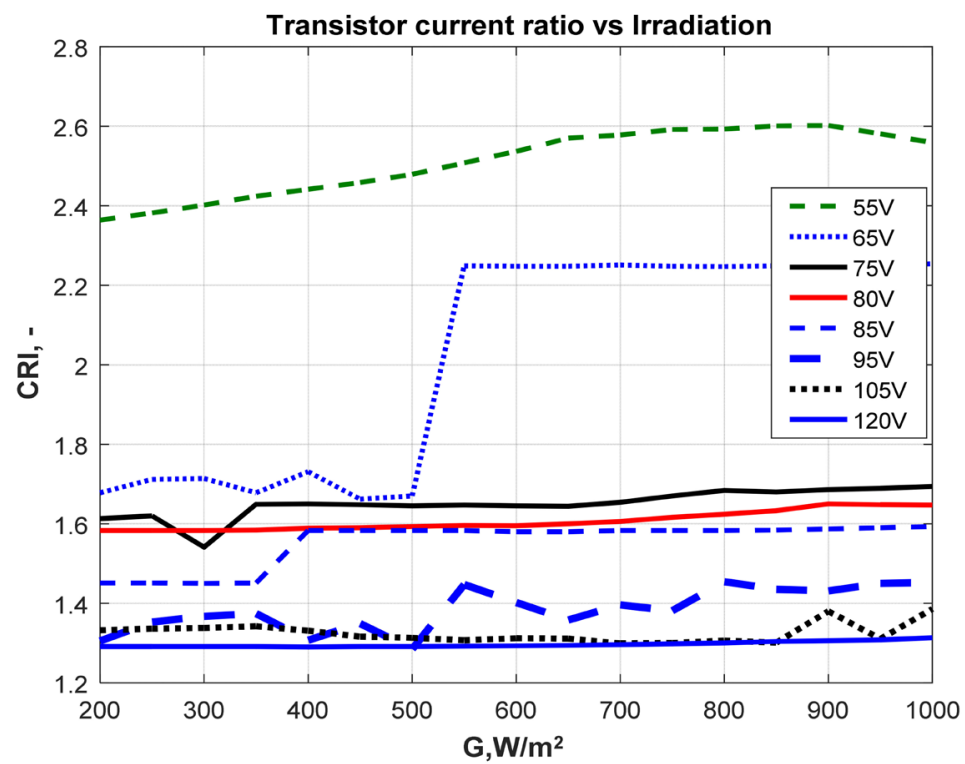

(a)

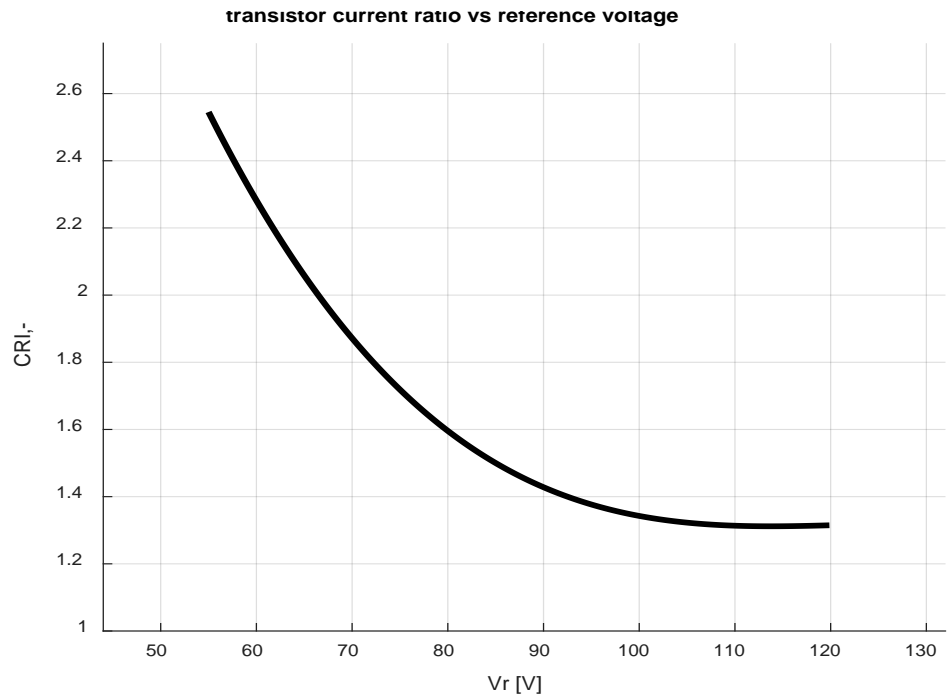

(b)

Figure 13. CRI at various irradiation \& constant Vref. (a) Instantaneous CRI; (b) Average CRI. 
The derived mathematical expression for average current ratio is stated in (20).

$$
C_{R I}(V r i)=\frac{\sum_{1}^{N g} I_{r m s}\left(G_{i}\right) / I_{a v g}\left(G_{i}\right)}{N g} .
$$

where, $I_{r m s}\left(G_{i}\right)$ and $I_{a v g}\left(G_{i}\right)$ are the RMS and average transistor currents at given irradiation level; $\mathrm{Ng}=17$ are the number of simulated values of Sun irradiation $G_{i}=400 \ldots 1000 \mathrm{~W} / \mathrm{m}^{2}$.

Refer to Figure $12 C_{R I}$ is converted into continuous function using spline interpolation with expression stated in (21).

$$
C_{R I}\left(V_{r i}\right)=a_{C 4} Z_{1}^{4}+a_{C 3} Z_{1}^{3}+a_{C 2} Z_{1}^{2}+a_{C 1} Z_{1}+a_{C 0},
$$

where, $Z_{1}=\left(V_{\text {ref }}-87\right) / 19, a_{C 4}=2.6 \times 10^{-16}, a_{C 3}=-0.029, \quad a_{C 2}=0.16$, $a_{C 1}=-0.27, a_{C o}=1.5$.

As displayed on Figure 13 the chopper losses become large at low reference voltages, while the signal quality becomes better and enhanced at larger values of reference voltage where $C_{R I} \rightarrow \cong 1$. This is the ideal case where the RMS current equals the average value.

\section{4) Transistor losses and the duty cycle}

Figure 14 illustrates the chopper losses with respect to the duty cycle for three values of reference voltage of $80 \mathrm{~V} \& 120 \mathrm{~V}$, where it can be shown that there are a concrete values of $D$ at which the chopper switch produces great losses and generates excess heat.

Furthermore, at large values of $D$ these losses became minimum. The mathematical expression presents this change of losses is stated in (22) at $V_{\text {ref }}=120 \mathrm{~V}$.

$$
P_{Q D}(D)=a_{p 3} Z^{3}+a_{p 2} Z^{2}+a_{p 1} Z+a_{p 0}
$$

where, $Z=\frac{D-0.56}{0.013}, a_{p 3}=0.011, a_{p 2}=-0.017, a_{p 1}=-0.043, a_{p 0}=0.77$.

\subsection{Daily \& Annually Estimated Transistor Losses}

In order to estimate the daily and annually transistor loses, first the daily profile of solar irradiation for certain site with latitude and longitude angles under clear sky is derived. Second, transistor loss expression in terms of solar irradiation is formulated, then the obtained expression is projected over the daily profile of the solar irradiation for certain day of the year, and finally the annual transistor losses are stated.

\subsubsection{Solar Irradiation Profile}

Suppose that the described chopper circuit is connected to a PV panel located in city of Hebron, Palestine with latitude and longitude coordinates are: $31^{\circ} 31^{\prime} 45.66^{\prime \prime} \mathrm{N}$ and $35^{\circ} 5^{\prime} 37.68^{\prime \prime E}$. According to Figure 15 the simple and approximated equation for solar irradiation is given by (23) [17] [18]. 


$$
G(t)=G_{\max } \sin \left(\frac{\pi}{T}\left(t-t_{S R}\right)\right), t_{S R} \leq t \leq T+t_{S R} .
$$

where, $G_{\max }$ is the radiation at noon time with values of $1000 \mathrm{~W} / \mathrm{m}^{2}, t_{S R}$ is the sun rise time for given day, and $T$ is the day duration.

These parameters are briefly described in [17] [19]. Assuming clear sky conditions and negligible sunlight reflection, Figure 15 shows the irradiation level for last day of April, June, September \& December, where it can be shown that June month has the largest daylight time with 14 hours duration, while December has the approximately shorter daylight time with 9.9 hours duration.

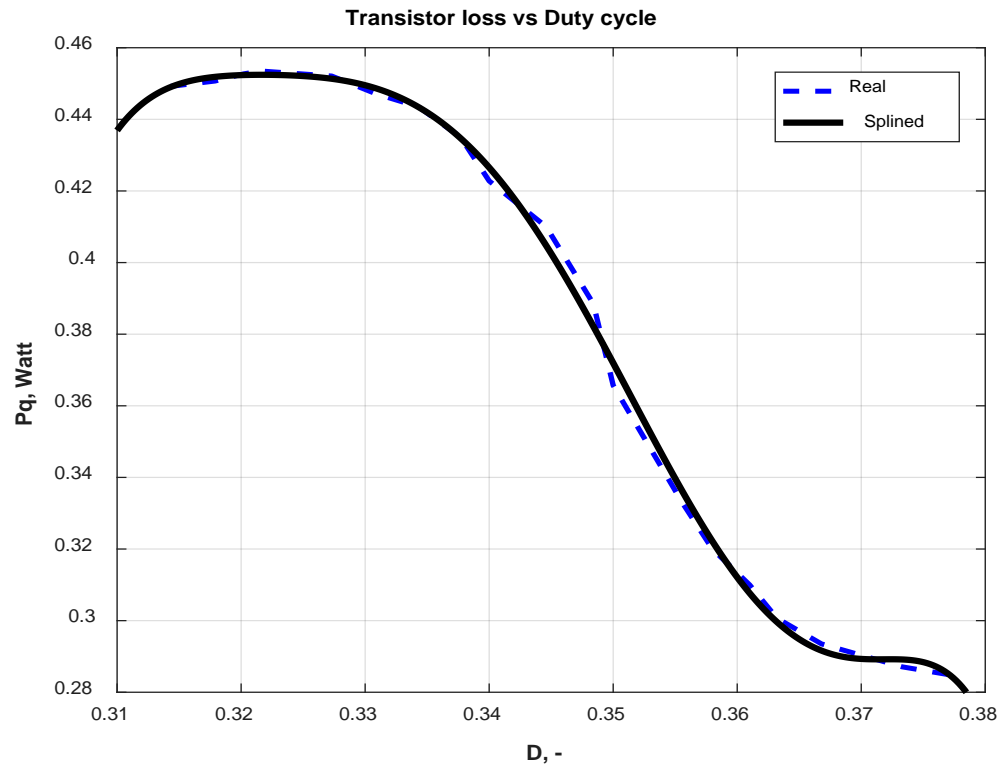

(a)

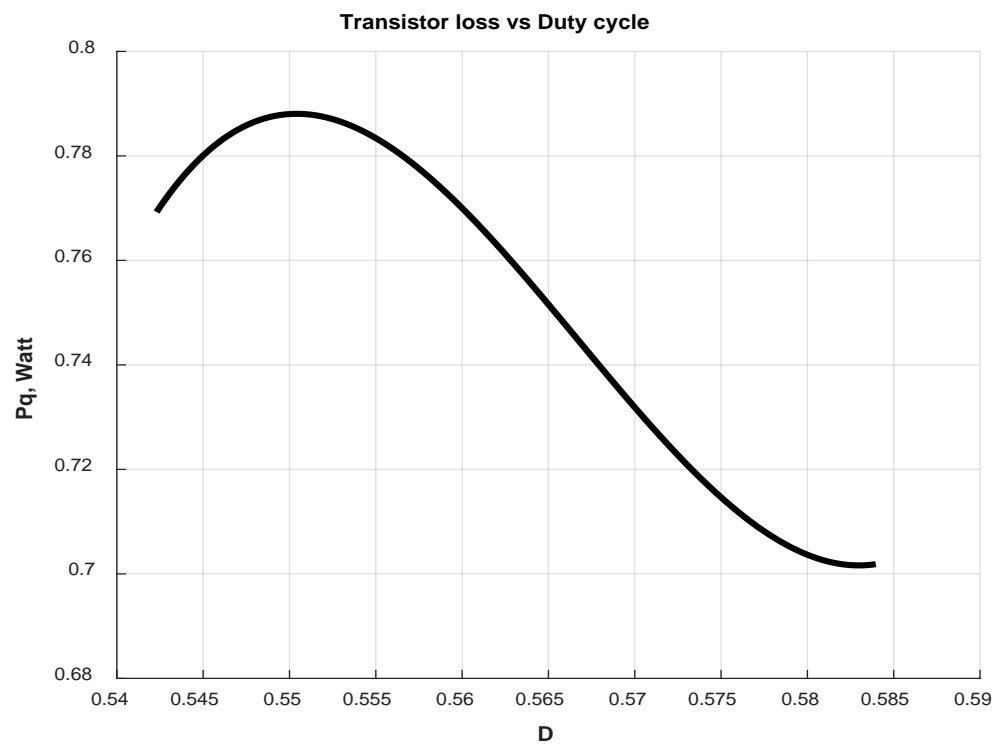

(b)

Figure 14. Transistor losses vs. duty cycle. (a) Vref $=80 \mathrm{~V}$; (b) Vref $=120 \mathrm{~V}$. 


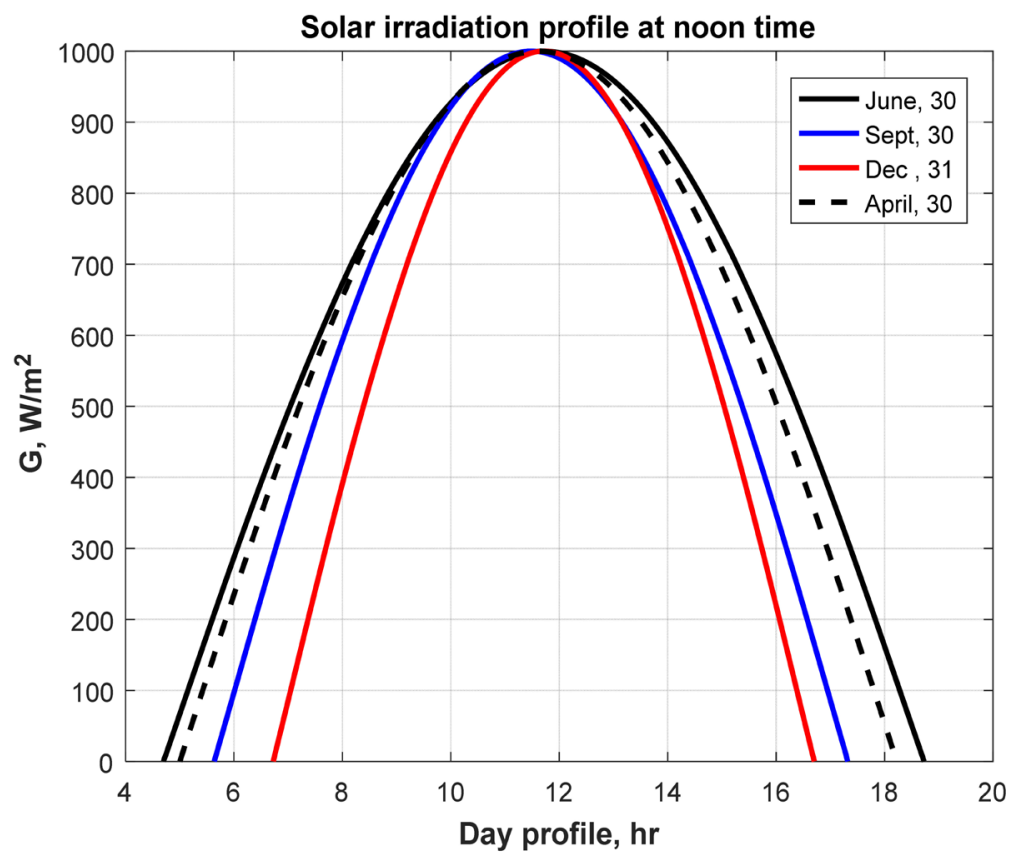

Figure 15. Solar irradiation for various months.

\subsubsection{Projection the Transistor Losses}

Having the solar irradiation profile for any day of the year, the transistor losses can be projected over that day, and the daily and annually losses can be precisely determined.

As first step transistor losses is interpreted in term of solar irradiation as shown on Figure 16, then $6^{\text {th }}$ order spline function is generated with high rate of coincidence between the simulated and spline curves function.

The generated spline function is expressed in (24) at fixed chopper reference voltage of $V_{\text {ref }}=120 \mathrm{~V}$.

$$
P_{Q D}(G)=a_{g 6} Z^{6}+a_{g 5} Z^{5}+a_{g 4} Z^{4}+a_{g 3} Z^{3}++a_{g 2} Z^{2}+a_{g 1} Z+a_{g 0} .
$$

where,

$$
\begin{aligned}
& Z=\frac{G-600}{250} ; a_{g 6}=-0.0083, a_{g 5}=0.01, a_{g 4}=0.04, \\
& a_{g 3}=-0.043, a_{g 2}=-0.066, a_{g 1}=0.062, a_{g 0}=0.78 .
\end{aligned}
$$

Now, substituting (23) in (24) yields expression stated in (25) for transistor losses in terms of maximum irradiation rate, sunrise time, daytime duration and solar declination angle for certain day of the year.

$$
Z=\frac{\left[\left(G_{\max } \sin \frac{\pi}{T}\left(t-t_{S R}\right)\right)-600\right]}{250} .
$$

Figure 17 shows the variation of these losses during day time in accordance with solar irradiation values displayed on Figure 15. 


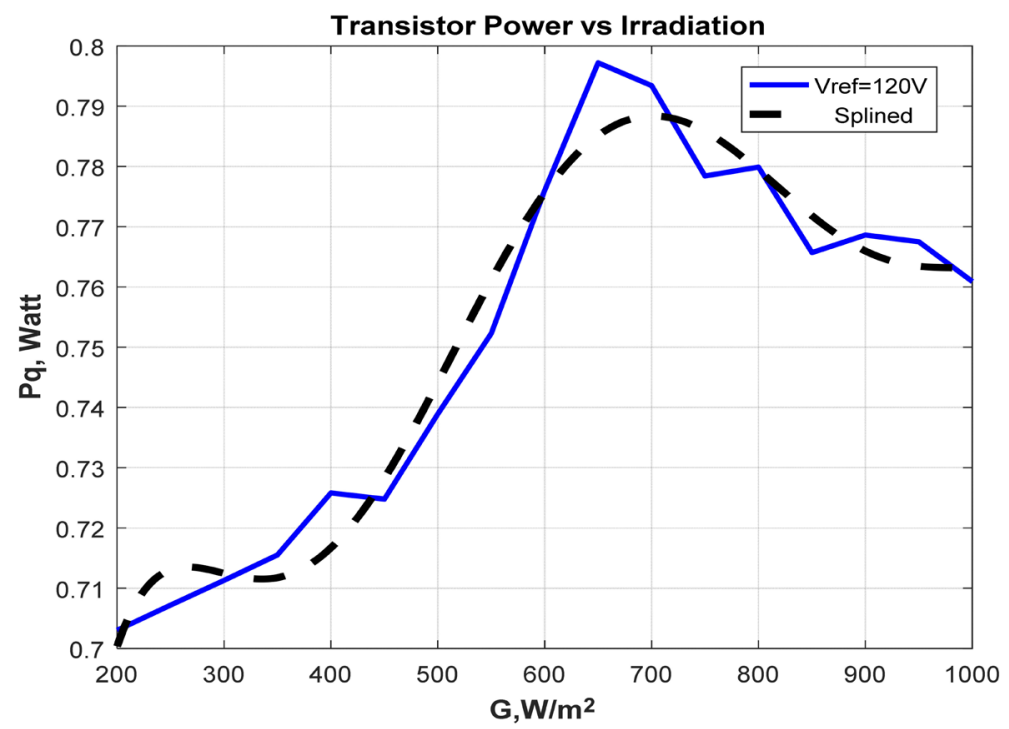

Figure 16. Transistor losses at vref $=120 \mathrm{~V}$.

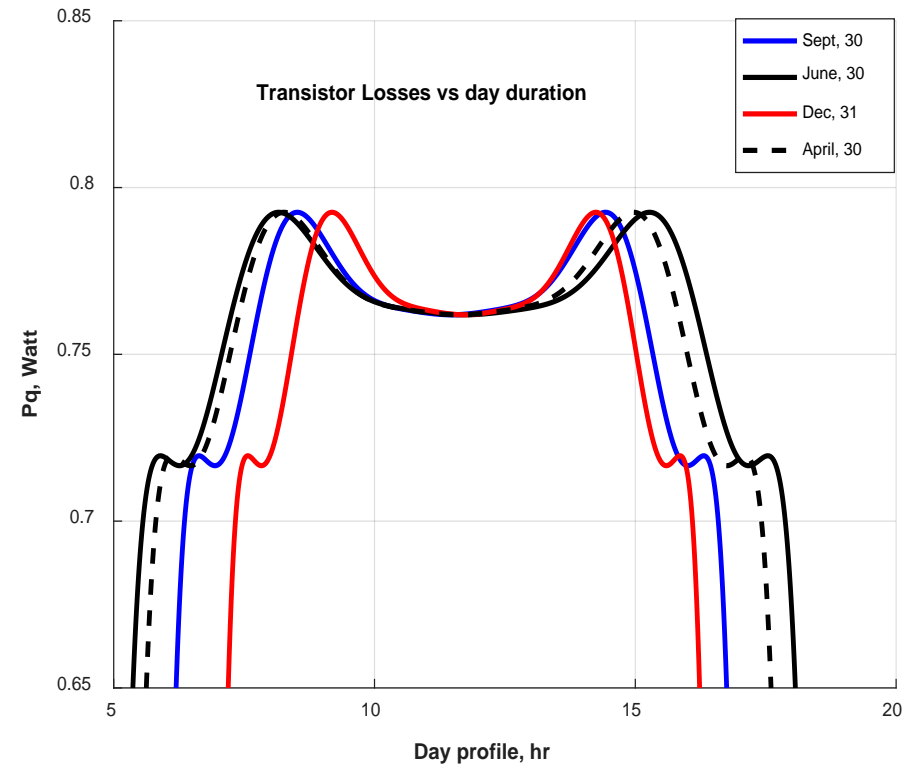

Figure 17. Transistor losses vs. day duration.

As shown from this figure at local noon time [19] [20] the transistor approximately has the same losses for all months, while at moderate early morning and late afternoon time these losses increased significantly. The reason for that is the increase in duty cycle according to Figure 9 which in turn increases the transistor conduction time causing additional losses to be generated.

\subsubsection{Average Daily Transistor Losses}

In addition to circuit current, transistor bulk resistance during on-state mode, transistor losses changes as well during the daytime from sunrise to sunset interval, therefore the average daily transistor losses vary as well, and depend on the day duration which is variable among the 365 days of the year. 
Way out from Figure 18 where transistor losses for the longest and shortest days of the year are displayed. The average daily power can be calculated taking into account (23) by assuming that only $a_{g 0}, a_{g 1}$, and $a_{g 2}$ exist in order to simplify the average power expression without significantly affecting the accuracy of the result. Then, the obtained result is multiplied by loss correction factor $K_{q}$ in order to compensate the stated assumption regarding power coefficients $a_{g 3}-a_{g 6}$.

To do that, first the maximum occurred transistor losses are determined at the longest day of the year which is $23 \mathrm{rd}$ of June with day number of $n_{1}=173$ corresponding to maximum day duration $T_{\max }$ is stated in (26).

$$
\begin{aligned}
P_{Q A V}\left(T_{\max }\right)= & \frac{K_{q}}{T_{\max }} \int_{t_{S R}}^{t_{S S}} P_{Q D}\left(n_{1}\right) \mathrm{d} t=a_{g 2}\left(\frac{A_{m}^{2}}{2}-\frac{4 A_{m} B_{m}}{\pi}+B_{m}^{2}\right) \\
& +a_{g 1}\left(\frac{2 A_{m}}{\pi}+B_{m}\right)+a_{g 0} .
\end{aligned}
$$

where $A_{m}=\frac{G_{\max }}{250}, B_{m}=2.4$ and $K_{q}=1.12$.

Analytically solving this equation and refer to Figure 18 it's shown that, the obtained average losses are 0.77 Watt which fits with the displayed performance. Therefore, the average daily losses for any day of the year can be expressed according to (27).

$$
P_{\mathrm{QAV}}(n)=\frac{T(n)}{T_{\max }} P_{\max }, n=1 \sim 365 \text { days. }
$$

The simulation results of power loss equation is displayed on Figure 19 Where it's shown that the maximum daily transistor losses occur during summer time with maximum value on June $23^{\text {rd }}$. Combining displayed data on Figure 18 and Figure 19 the dissipated energy in the transistor is calculated according to (28) with results displayed on Figure 20.

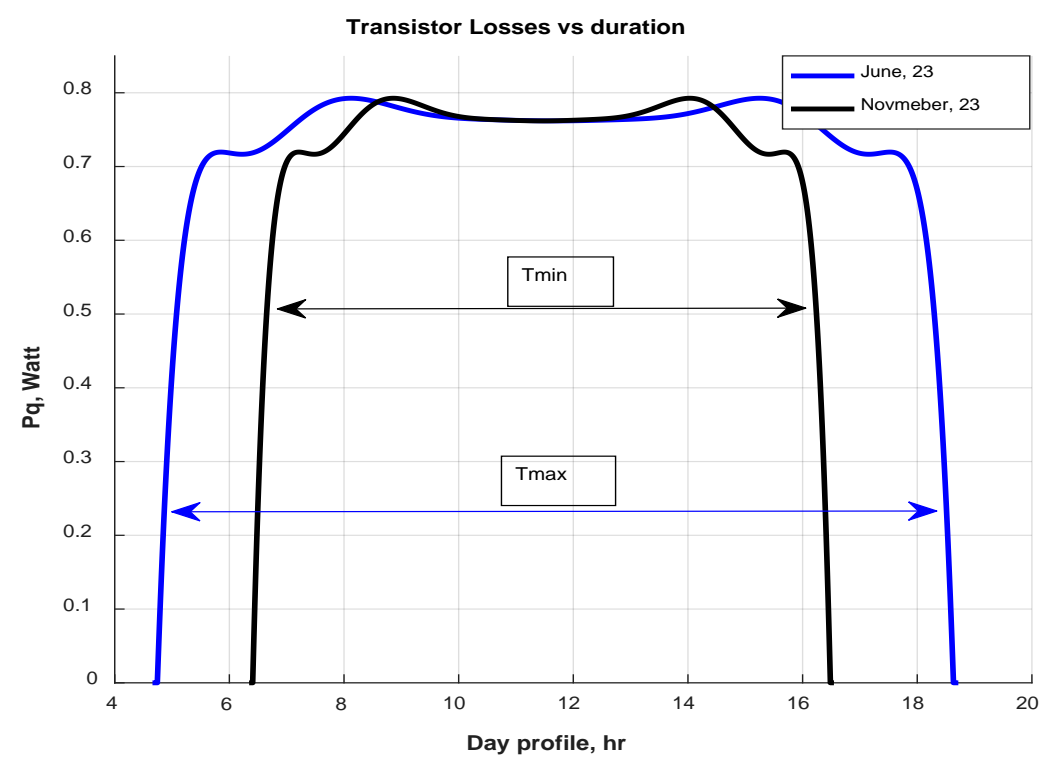

Figure 18. Transistor losses limit. 


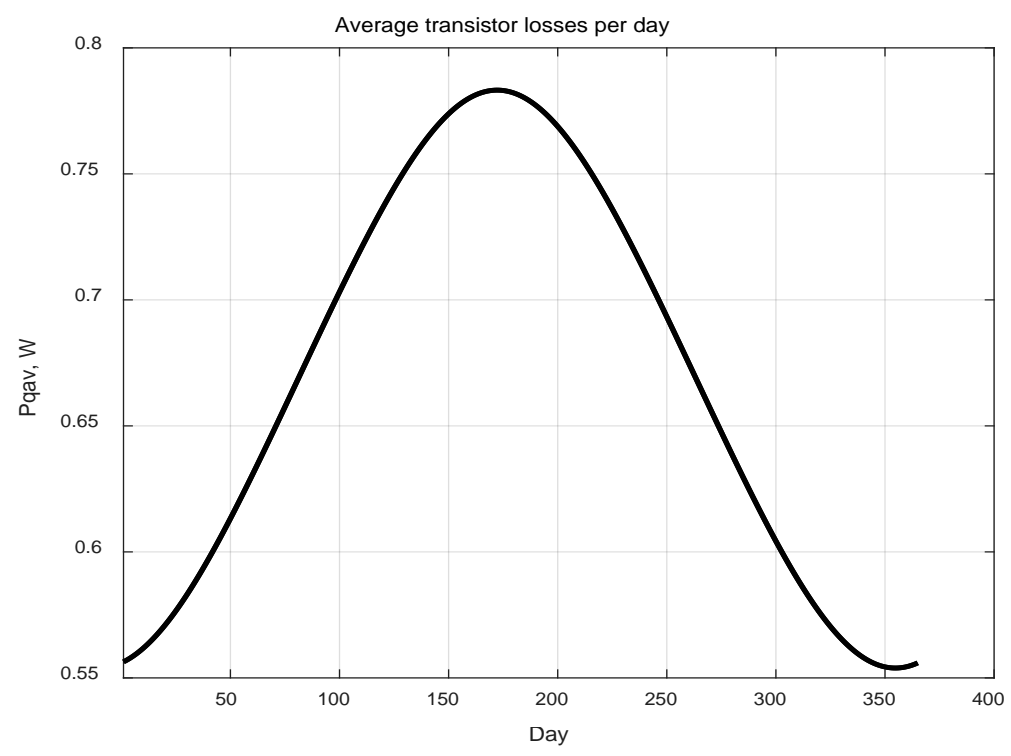

Figure 19. Average transistor losses per day.

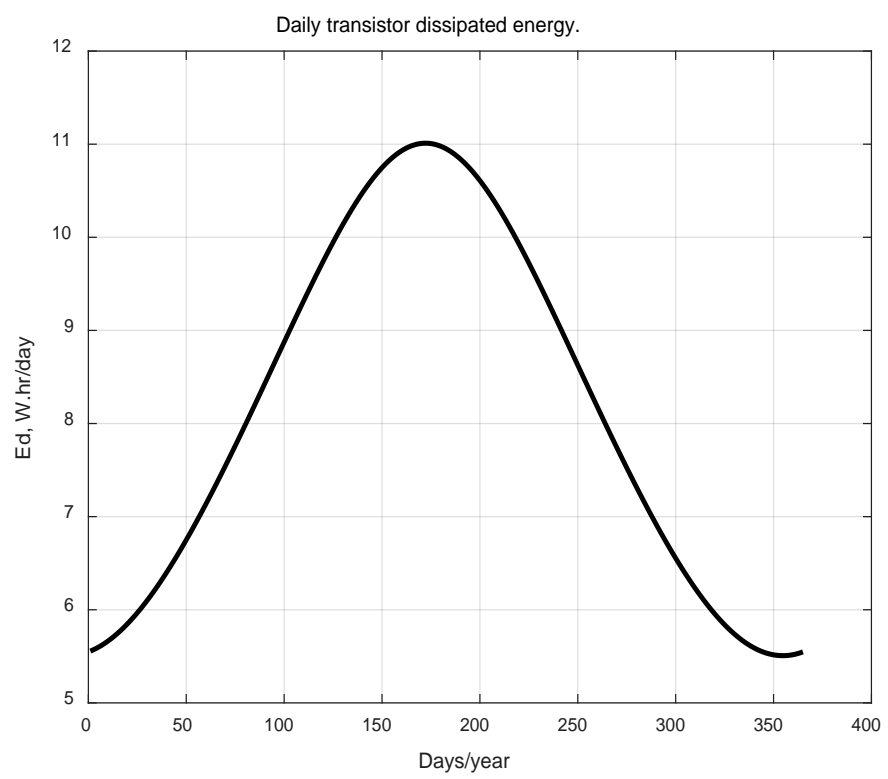

Figure 20. Dissipated energy per day.

$$
E_{d}(n)=P_{\mathrm{QAV}}(n) \cdot T(n), \quad n=1 \sim 365 .
$$

The dissipated in the transistor annual energy losses is expressed in (29).

$$
E_{a n n}=\sum_{n=1}^{365} P_{Q A V}(n) \cdot T(n) .
$$

As a result of applied mathematical approach for estimating the transistor energy losses the total dissipated annual energy in the transistor is around $\mathbf{2 9 7 0}$ W.hr/yr.

\section{Conclusions}

The present work creates new aspects for further research and a comparison 
analysis between various types of DC choppers. The simulation results stated that chopper behavior varies in a wide range as the solar irradiation, chopper reference voltage and duty cycle vary as well. The following key points can be underlined:

- The conducted research just targeted the occurred losses in form of dissipated energy converted into heat in the main transistor switch of the chopper, while the occurred losses in the rest of chopper elements can be subject to future research tasks.

- During the daylight time as the solar irradiation changes continuously at a given reference voltage causes a nonlinear change in the transistor current with a peak value at solar irradiation of $700 \mathrm{~W} / \mathrm{m}^{2}$ resulting in maximum dissipated power.

- Boosting up the chopper voltage to greater values far from the panel rated voltage at maximum power resulting in heavy drawn transistor current and dissipated power.

- Furthermore, boosting up the voltage to greater values causes a further decrease in the current ratio representing the relationship between average and RMS transistor currents. This indicator means that as the RMS current closes to the average the transistor should be exposed to less current stresses and less dissipated power in form of heat.

- Regulating the chopper voltage throughout its duty cycle at given solar irradiation causes a significant change in losses with maximum values at the certain reference voltage.

- Transistor losses changes during the daytime profile and varies throughout the year. Transistor chopper has great losses before and after noon time, while at exact local noon time thee losses drops slightly.

- The daily sunlight duration varies among the year with the longest day in June and the shortest in November resulting in variable dissipated power losses and energy.

Having the total transistor dissipated power and energy a comparison analysis with respect to the panel annual energy can be done.

In addition to that an optimizing procedure can be applied when selecting different switches regarding the occurred losses and dissipated energy.

\section{Conflicts of Interest}

The authors declare no conflicts of interest regarding the publication of this paper.

\section{References}

[1] Masters, G.M. (2004) Renewable and Efficient Energy Systems. Wiley, Hoboken, New Jersey, 528-565. https://doi.org/10.1002/0471668826

[2] Baharudin, N.H., Mansur, T.M.N.T., Hamid, F.A., Ali, R. and Misrun, M.I. (2017) Topologies of DC-DC Converter in Solar PV Applications. Indonesian Journal of Electrical Engineering and Computer Science, 8, 368-374. 
https://doi.org/10.11591/ijeecs.v8.i2.pp368-374

[3] Mrutyunjay, D. (2015) Design Aspects of DC-DC Boost Converter in Solar PV System by MPPT Algorithm. International Journal of Applied Science Engineering and Management, 1, 36-45.

[4] Khader, S. and Daud, A.-K. (2020) A Comparative Analysis between Various Filters for Three Phase Current Source Inverter. International Advance Journal of Engineering Research, 3, 1-14.

[5] Yi C.Y., Liao T.F., Dong C.W., Zhang H.W. and Xue J.X. (2014) Study on Harmonic Current Detection Method for Single-Phase PV Inverter. 2014 China International Conference on Electricity Distribution (CICED), Shenzhen, China, 23-26 September 2014, 1621-1624. https://doi.org/10.1109/CICED.2014.6991980

[6] Huang, H.H., Xue, H., Liu X. and Wang, H.X. (2013) The Study of Active Power Filters Using a Universal Harmonic Detection Method. 2013 IEEE ECCE Asia Downunder, Melbourne, VIC, Australia, 3-6 June 2013, 591-595. https://doi.org/10.1109/ECCE-Asia.2013.6579158

[7] Marouane, R. and Bacha, F. (2009) A Maximum-PowerPoint Tracking Algorithm Applied to a Photovoltaic Water-Pumping System. Proceeding of the 8th International Symposium on Advanced Electromechanical Motion Systems and Electric Drives Joint Symposium, 1-3 July 2009, IEEE Explore Press, Lille, 1-6. https://doi.org/10.1109/ELECTROMOTION.2009.5259078

[8] Vujacic, M., Hammam, M., Sandvik, M. and Grand, G. (2018) Analysis of DC-Link Voltage Switching Ripple in Three-Phase PWM Inverters. Energies, 11, 471-485. https://doi.org/10.3390/en11020471

[9] Tsuruta, Y. and Kawamura, A. (2015) Loss Analysis of High Power Chopper by Under-Zero Current Switching. IEEJ Journal of Industry Applications, 4, 31-39.

[10] Masters, G.M. (2013) Renewable Andefficient Electricpower Systems. John Wiley \& Sons, Hoboken, New Jersey.

[11] Suehiro, Y., Yamaguchi, K. and Ito, Y. (2009) Current-Resonant DC-DC Converter Designed to Achieve 95\% of Total Efficiency in Power Conditioner for Fuel Cell. INTELEC 2009-31st International Telecommunications Energy Conference, Incheon, Korea (South), 18-22 October 2009, 1-6. https://doi.org/10.1109/INTLEC.2009.5351843

[12] Onyebuchi, O.C. (2019) Power Loss Analysis Model of a DC-DC Buck-Boost Converter with an Interfaced Three Phase Inverter for Medium Voltage Application. Journal of Asian Scientific Research, 9, 100-115. https://doi.org/10.18488/journal.2.2019.98.100.115

[13] Appelbaum, J. and Bany, J. (1979) Performance Analysis of DC Motor Photovoltaic Converter System. Solar Energy, 22, 439-445. https://doi.org/10.1016/0038-092X(79)90173-7

[14] Abu-Aligh, M. (2011) Design of Photovoltaic Water Pumping System and Compare It with Diesel Powered Pump. Jordan Journal of Mechanical and Industrial Engineering, 5, 273-280.

[15] Khader, S. and Daud, A.-K. (2013) PV-Grid Tie System Energizing Water Pump. Journal of Smart Grid and Renewable Energy, 4, 409-418.

https://doi.org/10.4236/sgre.2013.45047

[16] SUNPOWER Datasheet, SPR-315E-WHT-D. http://www.solardesigntool.com/components/module-panel-solar/Sunpower/21/SP R-315E-WHT-D/specification-data-sheet.html 
[17] Matlab and Simulink (2016) The Mathworks, Inc., VersionR2016b. http://www.mathworks.com

[18] Krivoshein, Y.O., Tolstykh, A.V., Tsvetkov, N.A. and Khutornoy, A.N. (2020) Mathematical Model for Calculating Solar Radiation on Horizontal and Inclined Surfaces for the Conditions of Yakutsk. IOP Conference Series. Earth and Environmental Science, 408, 1-8. https://doi.org/10.1088/1755-1315/408/1/012002

[19] Daud, A.-K. and Mahmoud, M.M. (2005) Solar Powered Induction Motor-Driven Water Pump Operating on a Desert Well, Simulation and Field Tests. Renewable Energy, 30, 701-714. https://doi.org/10.1016/j.renene.2004.02.016

[20] Nasrin, M.S., Chakrabarty, A.K., Barman, M.C., Saha, S.K. and Rahman, M.M. (2017) Sunrise and Sunset Time Prediction in a Specific Latitude. IOSR Journal of Mathematics, 13, 1-7. 